\section{Gastric barotrauma}

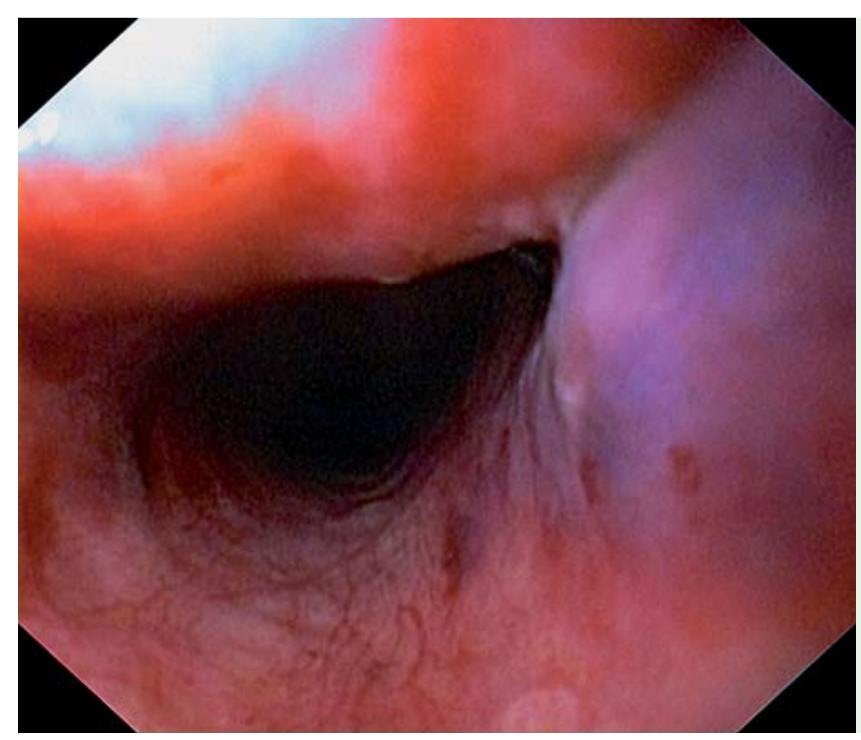

Fig. 1 Hematoma in
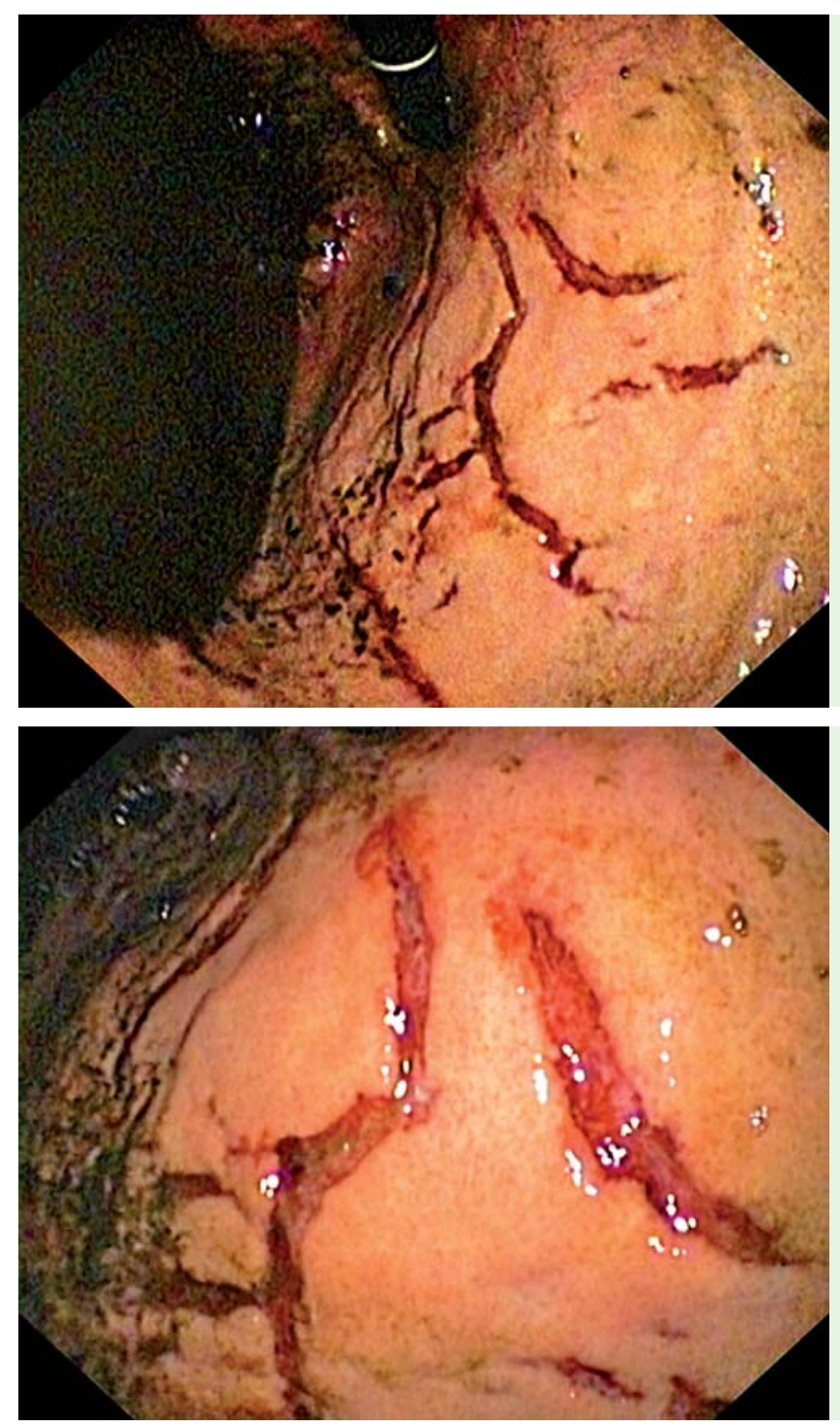
the proximal esophagus.

A 67-year-old woman with anti-neutrophil cytoplasmic antibody (ANCA)-positive vasculitis and related renal involvement was admitted to the emergency department with hemoptysis and respiratory failure. She had signs of respiratory distress, a peripheral $\mathrm{O}_{2}$ saturation of $76 \%$, hypotension and tachycardia. Noninvasive positive pressure ventilation was performed, but poor adaptation of the patient led to orotracheal intubation. During this procedure, after bag-mask ventilation, the esophagus was intubated twice with positive pressure, due to technical difficulties. Effective invasive ventilation was afterwards achieved. On the following day, the patient remained in the intensive care unit and an upper digestive endoscopy was performed because blood in the nasogastric tube and a fall in the patient's hemoglobin level were detected. A proximal esophageal hematoma was observed, compatible with trauma from the ventilation tube ( $\bullet$ Fig. 1) and tortuous longitudinal tears were seen in the lesser curvature of the proximal gastric body ( $\bullet$ Fig. 2 , - Fig.3). These lesions were suggestive of gastric barotrauma, a condition that arises when sudden gaseous distension of the gastric cavity occurs at high pressure and can lead to transmural rupture of the gastric wall. Thus, most of the cases described in the medical literature were approached surgically [1]. Barotrauma occurs in the lesser gastric curvature, probably because this part of the stomach has a lower capacity for distension, owing to the lack of mucosal folds [1,2]. Gastric barotrauma has been reported after bag-mask ventilation, noninvasive positive pressure ventilation, air swallowing during diving and cardiopulmonary resuscitation [1-4]. In the present case, conservative management was successful.

Fig. 3 Closer view of the tears in the gastric body.

Endoscopy_UCTN_Code_CCL_1AB_2AD_3AF

Competing interests: None

\section{Ricardo Küttner Magalhães ${ }^{1}$, Ricardo Marcos-Pinto' ${ }^{1}$, Sara Silva², Isabel Pedroto ${ }^{1}$}
${ }^{1}$ Department of Gastroenterology, Hospital Santo António, Centro Hospitalar do Porto, Portugal
2 Department of Internal Medicine, Hospital Santo António, Centro Hospitalar do Porto, Portugal 


\section{References}

1 Spoormans I, Van Hoorenbeeck K, Balliu L et al. Gastric perforation after cardiopulmonary resuscitation: review of the literature. Resuscitation 2010; 81: $272-280$

2 Jalali SM, Emami-Razavi H, Mansouri A. Gastric perforation after cardiopulmonary resuscitation. Am J Emerg Med 2012; 30: 2091

3 Malik SM, Rockacy M, Al-Khafaji A. Bleeding after bagging. Diagnosis: Gastric rupture and massive pneumoperitoneum secondary to barotrauma from bag ventilation. Gastroenterology 2011; 141: e16-17

4 Titu LV, Laden G, Purdy GM et al. Gastric barotrauma in a scuba diver: report of a case. Surg Today 2003; 33: 299-301
Bibliography

Dol http://dx.doi.org/

10.1055/s-0034-1377940

Endoscopy 2014; 46: E564-E565

(c) Georg Thieme Verlag KG

Stuttgart · New York

ISSN 0013-726X

\section{Corresponding author}

Ricardo Küttner Magalhães, MD

Department of Gastroenterology

Hospital Santo António, Centro Hospitalar do Porto Largo Prof. Abel Salazar

4099-001 Porto

Portugal

rkuttner@gmail.com 